\title{
0 atual programa político petista no contexto de uma esquerda em crise
}

Maria Izabel Lagoa ${ }^{1}$

Os últimos trinta anos do século XX testemunharam inegavelmente uma crise estrutural não só na forma estrutural do capitalismo, mas também das estruturas e conformações ideo-políticas do sistema. Esta crise do capital foi também acompanhada por uma crise material e ideológica dos países do chamado "socialismo real", particularmente do leste europeu, e consequentemente do marxismo herdeiro da III Internacional.

Esta crise do "socialismo real", que teve na queda do muro de Berlim e na dissolução da URSS seus momentos emblemáticos, desencadeou uma revisão nas principais elaborações teórico-políticas do pensamento marxista, desaguando na chamada "crise do marxismo". Diante deste cenário geral de pseudocrise teórica do marxismo, uma parte da esquerda encontra no presente a possibilidade de realizar uma "autocrítica" de seu passado e abandonar as antigas determinações políticas de classe e de revolução, uma vez que acusam a emergência de uma crise do movimento socialista fundamentada na desqualificação da idéia de revolução, pois sua sustentação, a obra marxiana apresentaria diversos "equívocos"2.

Entretanto os indícios do que viria se tornar esta revisão já se encontrava presente mesmo antes da derrocada do "socialismo real". Como ressalta Anderson, a chamada

$-\cdots+-$

1 Mestranda do curso de pós-graduação em Ciências Sociais da Faculdade de Filosofia e Ciências da UNESP/ Marília.

2 Ver José Paulo Netto. Crise do socialismo e ofensiva neoliberal. 3ª ed. São Paulo, Cortez, 2001.

$\mathbf{6 2}$ O atual programa político petista no contexto de uma esquerda em crise 
"crise do marxismo" teve sua gênese dentro do espaço geográfico da Europa ocidental, mais precisamente na região latina, formada pela Itália, Espanha e França. As derrotas acumuladas pela esquerda nos diversos países do sul europeu representaram um golpe desmoralizante para todos aqueles que esperavam um novo despertar do movimento operário europeu, e, portanto, "foi aqui que a chamada "crise do marxismo" teve sua origem e significado $o^{3}$. Foi nesta região que o eurocomunismo ${ }^{4}$, surgido da crítica ao andamento da revolução na URSS e da revolução na China, representou as maiores oportunidades para uma emergência significativa do movimento operário no ocidente. Todavia a socialdemocracia se apresentou mais eficiente no campo institucional, levando o eurocomunismo a derrota. Assim, a emergência da chamada "crise do marxismo" foi um fenômeno latino, pois foi justamente nos três principais países - França, Itália e Espanha - que as oportunidades do eurocomunismo pareciam maiores e onde o esvaziamento da esquerda foi mais acentuado.

Com o agravamento das derrotas da esquerda em outras regiões, esta pseudocrise e conseqüentemente as revisões frente ao arcabouço teórico tradicional se expandiram pelo globo. Entretanto, tais revisões muito mais pautadas na simples negação do passado do que numa análise profunda dos erros e acertos cometidos, deu origem a uma esquerda que ao exorcizar seu passado abandona todo seu caráter revolucionário.

A segunda grande derrota da esquerda esteve na crise do Welfare State implantado nos países do norte Europeu, que apesar de apresentar-se como uma alternativa dentro do sistema capitalista insere-se no quadro mais amplo das conquistas do movimento operário. Esta crise muito mais resultado da crise do capital nos anos 70 , levou a exortação das formulas econômicas keynesianas na qual se baseava o Welfare State. Insere-se neste contexto a própria derrocada das tentativas de desenvolvimento dos paises do III mundo, que foi paralisada pela falta de financiamento externo derivada da crise do capital.

Assim, tanto a esquerda do sul quanto a do norte falharam ao proporem a reuni-

$-\cdots-\cdots$

3 Ver Perry Anderson. A crise da crise do marxismo: introdução a um debate contemporâneo. São Paulo, Brasiliense, 1984 e Um mapa da esquerda na Europa ocidental. Rio de Janeiro, Contraponto, 1996.

40 eurocomunismo se diferenciava das orientações da Revolução de outubro e o regime que dela se derivou, defendendo em contrapartida uma via pacífica, gradual e constitucional para o socialismo.

5 Salvo algumas exceções como a escola de Budapeste, com Luckács e seus discípulos.

cadernos cemarx, $n^{0}-2-2005 \mid 63$ 
ficação e renovação da teoria marxista ${ }^{5}$ com a prática em um movimento revolucionário de massas através de um reformismo que buscava privilegiar o campo do parlamento. Sem dúvidas, alguns privilégios foram alcançados para a classe trabalhadora, como a implantação de políticas de assistência social articulada a uma política econômica que associava emprego, investimento e consumo. Entretanto, em momento algum esta esquerda foi capaz de articular as condições para a construção da hegemonia do movimento operário que possibilitasse a superação de sua subalternidade frente ao capital.

Tal acomodação parlamentar pautada na aceitação de que a prática parlamentar é a única maneira legítima de contestar a ordem do capital, acarretou em um conseqüente enfraquecimento das potencialidades de luta do mundo do trabalho. Segundo Mészáros, isto significou uma cisão no movimento entre o "braço político" e o "braço sindical' do trabalho, onde ao "braço político" caberia o papel de servir ou representar, codificando legislativamente, os interesses da classe trabalhadora organizada nas empresas industriais capitalistas pelos sindicatos de cada ramo do "braço sindical". Entretanto, com o tempo esta ilusão foi desmantelada, pois o "braço político" não utilizou de seu mandato político em colaboração com o "braço sindical, mas ao invés disso utilizou das regras do jogo parlamentar com a finalidade de subordinar os sindicatos a seu favor e das determinações políticas finais do capital, impostas através do Parlamento ${ }^{7}$.

A consequência do fracasso de tentar adequar uma política revolucionária com uma prática revolucionária foi necessariamente uma ausência geral de um pensamento estratégico pela esquerda dos países avançados. Este processo se agrava com o colapso do "socialismo real", simbolizado pela queda do muro de Berlim e pela dissolução da URSS, aonde a "esquerda tradicional" que já vinha sendo alvo de inúmeras críticas e revisões enfrenta agora sua maior revisão, justamente por aqueles intelectuais que assumiram a idéia da existência de uma "crise do marxismo". Todavia, ao ser realizada por uma esquerda reformista, que antes de procurar construir as bases para uma prática ofensiva frente ao capital, adotou uma prática defensiva que acabava por reproduzir a subalternidade do mundo do trabalho dentro do sistema, essas críticas e

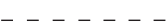

GVer István Meszaros. “Atualidade histórica da ofensiva socialista”. In: Para além do capital.In: São Paulo, Boitempo, 2002, p. 834.

7 Idem.

64 a atual programa político petista no contexto de uma esquerda em crise 
revisões longe de apresentarem uma positividade para a luta pela emancipação do homem, acabaram por levar a esquerda a um total recrudescimento. Esta retração do pensamento de esquerda acontece quando parte da direção político-cultural do movimento operário comunista pretende evitar que os erros cometidos no passado sejam repetidos, entretanto, ao invés de elaborar uma reflexão consistente, contentam-se em recusar sem nenhum tipo de mediação a prática vencida, o que não propiciou nenhum tipo de esclarecimento e, portanto nenhuma proteção quanto a possibilidade de repetir os mesmos erros ${ }^{8}$. Assim, ao formular uma crítica superficial ${ }^{9}$ sobre o passado, preocupada muito mais em exorcizar seus fantasmas, esta esquerda acaba reconhecendo a insuperabilidade da ordem capitalista e da institucionalidade liberaldemocrática, apresentando-se então como uma "esquerda democrática"10.

$O$ aspecto dramático colocado por esses diferentes acontecimentos e a emergência de uma crise dentro do pensamento da esquerda esta posto no avanço do neoliberalismo, pois, no momento em que a própria esquerda não mais se reconhece como agente da transformação social, libera o capital dos limites que a "ameaça comunista", enquanto seu maior oponente, colocava a sua completa dominação. Desse modo, o capital encontra-se sem nenhum entrave a não ser suas próprias contradições para materializar-se como "pensamento único" e intransponível.

Diante desse novo contexto a esquerda procura reestruturar-se sobre novas bases. A marca registrada desta moderna esquerda, que será responsável pelo enfraquecimento do movimento operário revolucionário, esta em não reconhecer a centralidade do mundo do trabalho no processo histórico, além de abstrair de suas teses a idéia de socialismo como teleologia da ação revolucionária, ressalvando em seu lugar a necessidade de se alargar a cidadania e a democracia.

No Brasil, mais especificamente, esta "autocrítica" pode ser percebida no atual programa político petista, que apesar de não ser um partido de raiz nas principais orientações políticas do marxismo leninismo, insere-se num quadro mais geral dos partidos da esquerda trabalhista.

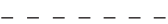

8 Ver José Chasin. A sucessão na crise e a crise na esquerda. São Paulo, Ensaio n 17/18, p.59

9 Não compreendem que a crise que abalou os diversos sistemas "socialistas" não se remete ao projeto socialista revolucionário e a constatação da impossibilidade da transição socialista, mas sim a uma crise de uma determinada forma histórica de transição. A esse respeito ver José Paulo Netto, op. cit.

10 Ver Del Roio, M. A crise do movimento operário. FREITAS, M.C. (org). A reivenção do futuro. São Paulo, Cortez, 1996.

cadernos cemarx, $n^{0}-2-2005 \mid 65$ 
Para podermos compreender o processo de formação do programa político que o PT apresenta atualmente não podemos esquecer que sendo herdeiro, admitindo ou não, da história da esquerda brasileira, encarna em si a particularidade histórica dessa esquerda.

A esquerda brasileira tem sua gênese diferentemente das de "tipo europeu", que nascem como continuidade revolucionária no momento em que a burguesia se torna contra-revolucionária. No Brasil, a formação econômico-social capitalista apresenta a especificidade de desde sua origem ter se subordinado estruturalmente aos pólos mais avançados do capitalismo. Nesse sentido, a burguesia brasileira sempre foi associada, e, portanto nunca se constituiu como revolucionária, tendo sido incapaz de exercer seu papel histórico de levar até o fim a formação do capitalismo no Brasil e conseqüentemente completar a revolução burguesa no país ${ }^{11}$. Desse modo a esquerda brasileira surge na lacuna deixada por esta burguesia e por um complexo teórico ainda muito deficitário ${ }^{12}$. Diante desta origem e do posterior desenvolvimento histórico da esquerda tradicional brasileira ${ }^{13}$, aqui entendido principalmente o Partido Comunista Brasileiro(PCB), acaba assumindo a tarefa que seria da burguesia brasileira, de completar o capitalismo e a revolução burguesa no país.

No momento em que o PT emerge da insatisfação dos trabalhadores do movimento sindical e outros movimentos sociais, ele surge como a possibilidade de superar

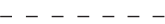

11 José Ver Chasin. Sucessão na crise e a crise da esquerda. São Paulo, Ensaio, n017/18.

12 Sobre a maneira como a teoria marxista penetra no Brasil ver: Antonio Carlos Mazzeo, M. I. Lagoa, (orgs). Corações vermelhos: os comunistas brasileiros no século XX. São Paulo: Cortez, 2003.; e Marcos Del Roio. “Os comunistas, a luta social e o marxismo", In: Marcelo Ridenti, Daniel Aarão. História do marxismo.Campinas: Editora Unicamp, 2002, vol. V.

13 Para uma análise do desenvolvimento histórico-político do PCB ver Mazzeo. Sinfonia Inacabada: a política dos comunistas no Brasil. São Paulo, Boitempo, 1999; J. A. Segatto. Breve História do PCB. São Paulo, LECH 1981 e Daniel Aarão. A revolução faltou ao encontro. São Paulo, Brasiliense, 1990.

140 PT afima-se como uma novidade na história da esquerda Brasileira, ver resoluções do $1^{\circ}$ Encontro Nacional, 1981, assim como autores Clóvis Bueno Azevedo. A estrela partida ao meio: ambigüidades do pensamento petista. São Paulo, Entrelinhas, 1995; M. Gadotti, P. Otaviano. Pra que PT: origem, projeto e consolidação do Partido dos Trabalhadores.São Paulo, Cortez, 1989; M. Kcek. A lógica da diferença: o Partido dos trabalhadores na construção da democracia brasileira. São Paulo: Atica, 1991.; R. Meneguello. PT: A Formação de um partido.Rio de Janeiro, Paz e Terra, 1989. Tais afirmações estabelecem tal novidade no vinculo operário do partido. Nesse sentido vamos ao encontro com Francisco de Oliveira em Qual é a do PT? In: Emir Sader (org). E agora PT: caráter e identidade. São Paulo, Brasiliense, 1986, que nega esse caráter, pois ele não leva em consideração as demais organizações de esquerda que estabeleceram tal vínculo ainda que mais tarde se desligassem.

66 - 0 atual programa político petista no contexto de uma esquerda em crise 
tais contradições. Assim, se podemos dizer que existe uma novidade ${ }^{14}$ no surgimento do PT, ela se encontra justamente nisto, de surgir como um partido extremamente vinculado aos movimentos sindicais e sociais em um momento em que o movimento operário internacional entra em refluxo.Todavia esta novidade não se apresenta como a solução as diversas questões pelas quais a esquerda brasileira enfrentou, de fato, essa novidade somente proporciona ao PT esta possibilidade de superação enquanto potencial, um "vir a ser". Todavia no transcorrer dos anos 80 , período de sua conformação enquanto partido, esse potencial é soterrado pelo mesmo fator que proporcionou seu surgimento, o espontaneísmo das massas ${ }^{15}$. Tal espontaneísmo não permitiu que o partido superasse o imediatismo de suas análises, impedindo que se realizasse uma profunda análise histórica da realidade brasileira e conseqüentemente a elaboração de um projeto político consistente.

Nos anos 90, quando o partido já se encontra prisioneiro do jogo eleitoral, a tendência histórica da esquerda brasileira se agrava com o complexo regressivo da esquerda mundial, levando o PT a se deslocar cada vez mais para o pólo da mera radicalidade burguesa, abstraindo a centralidade do trabalho na sociedade ao transitar de um discurso obreirista para um discurso societário global ${ }^{16}$. Esta tendência materializa-se em sua completude no $1^{\circ}$ Congresso do partido em 1991 e desenvolvese no transcorrer da década, ressalvando o PT com um partido moderado que procura atuar dentro das instituições e como principal defensor da democracia ${ }^{17}$.

Assim, o PT surge frente as mesmas questões que as diversas organizações políticas de esquerda no país enfrentaram, com o agravante de que ao renegar seu passado histórico perde a oportunidade de rever os erros cometidos e impedir que cometa os mesmos. Além disso, ao encarnar em si a própria crise da esquerda contemporânea e a particularidade histórica da esquerda brasileira, não consegue elaborar um projeto de transformação da sociedade que vá além da mera radicalidade da revolução burguesa.

\section{$--{ }_{--1-}$}

15 Quanto ao caráter espontaneísta que o PT absorver do movimento das massas ver Ricardo Antunes. A rebeldia do trabalho: 0 confronto operário no ABC. Campinas, Ensaio/Unicamp, 1992. A respeito da espontaneidade das greves do ABC paulista ver também Chasin em: “As máquinas param: germina a democracia". In: Revista Ensaio, $n^{\circ} 7$. São Paulo: Editora Escrita, abril de 1980 e Celso Frederico. A esquerda e o movimento operário 1964-1984: a reconstrução. Vol 3. Belo Horizonte, Oficina de livros, 1991.

16 Ver Francisco de Oliveira, op. cit.

17 Ver Diretório Nacional don PT (org). Partido dos Trabalhadores: Resoluções de Encontros e Congressos 19791998. São Paulo, Fundação Perseu Abramo, 1998.

cadernos cemarx, $n^{0} 2-2005 \mid \mathbf{6 7}$ 